\title{
Atrasos nos encaminhamentos de pacientes com câncer bucal: avaliação qualitativa da percepção dos cirurgiões-dentistas
}

\author{
Delayed referrals of oral cancer patients: \\ the perception of dental surgeons
}

Eduardo Madruga Lombardo ${ }^{1}$

Amanda Ramos da Cunha ${ }^{1}$

Vinicius Coelho Carrard ${ }^{2}$

Caren Serra Bavaresco ${ }^{1}$

${ }^{1}$ Serviço de Saúde Comunitária, Grupo Hospitalar Conceição. Araruama 487, São José. 99.155-370 Porto Alegre RS Brasil. eduardomlombardo@ gmail.com

${ }^{2}$ Departamento de Odontologia Conservadora (Patologia Bucal), Faculdade de Odontologia, Universidade Federal do Rio Grande do Sul.
Abstract The scope of this study was to verify the possible reasons to justify the delay in the referral of oral cancer patients to specialized health care sectors from the standpoint of the dental surgeons involved in Primary Health Care (PHC) in Porto Alegre, state of Rio Grande do Sul. This target public of this study was dental surgeons working in five different labor environments in PHC in Porto Alegre. Criteria for inclusion was dental surgeons graduated in and working in PHC. The data collection instrument was the focus group technique and application of a structured questionnaire. After data collection, interpretative analysis was conducted with classification of the information under four main headings: professional, team, community and services network. The results suggest that there are several factors associated with delayed in referral of patients with oral cancer to specialized health care sectors. These include omission of early diagnosis, lack of multidisciplinary work and insufficient attention to the need for joint community responsibility with patients for their own health status. It is also due to deficiencies in the health service network, specifically regarding the quality of communication between professionals at different levels of the health services.

Key words Delayed diagnosis, Primary health care, Dentist's behavior patterns
Resumo O objetivo deste estudo é verificar, na percepção dos cirurgiões-dentistas atuantes em Atenção Primária em Saúde (APS) em Porto Alegre (RS), quais as possíveis razões que justifiquem o atraso da chegada do paciente com câncer bucal aos setores de atenção em saúde de maior complexidade. O presente estudo teve como público-alvo cirurgiões-dentistas atuantes em cinco diferentes realidades laborais em APS em Porto Alegre. Foram utilizados como critérios de inclusão profissionais com formação em APS e que estivessem atuando na Atenção Básica. O instrumento para coleta de dados foi a técnica de grupo focal com aplicação de questionário estruturado. Uma vez coletados os dados, foi realizada análise interpretativa e categorização das informações em quatro eixos centrais: profissional, equipe, comunidade e rede de serviços. Os resultados sugerem que os seguintes fatores estão associados ao atraso da chegada do paciente com câncer bucal aos setores de atenção em saúde de maior complexidade: falha na identificação precoce, ausência de trabalho multidisciplinar, desvalorização da necessidade de corresponsabilização pela própria saúde por parte da comunidade e a deficiência da rede de atenção no que tange a qualidade da comunicação entre profissionais de diferentes níveis de atenção.

Palavras-chave Diagnóstico tardio, Atenção Primária à Saúde, Condutas na prática dos dentistas 


\section{Introdução}

O Instituto Nacional do Câncer (INCA) estimou a ocorrência de 14.170 novos casos de câncer de boca no Brasil, no ano de 2010, sendo $9.990 \mathrm{em}$ homens e 4.180 em mulheres ${ }^{1}$. Ao longo das últimas décadas, a taxa de mortalidade por câncer de boca tem se mantido em torno de 50\%. A região sul apresenta uma das maiores incidências de câncer no país, o que, em parte, pode ser explicado pelos altos níveis de consumo de taba$\mathrm{cO}^{2}$ e álcool ${ }^{3}$.

A questão do atraso no diagnóstico e no tratamento do câncer é fundamental para a redução da morbidade e mortalidade deste, já que sua ocorrência é importante na disseminação da doença, podendo levar à necessidade de abordagens terapêuticas mais radicais ${ }^{4}$. $\mathrm{O}$ atraso de diagnóstico é definido como o período desde o aparecimento de sintomas até o diagnóstico final ${ }^{5,6}$. Contudo, um número considerável de pacientes é diagnosticado quando a doença já se encontra em estágios avançados. Sabe-se que o atraso pode ser gerado por questões inerentes aos profissionais ou pacientes ${ }^{4}$. A duração do atraso do paciente varia na literatura desde menos de 1 mês até mais de 7 anos $^{6-8}$. Poucos estudos enfocaram nos fatores relacionados ao profissional ${ }^{6,9}$.

Diante do que foi exposto, o objetivo deste trabalho é esclarecer, a partir da percepção dos profissionais, as possíveis razões presentes na APS que justifiquem o atraso da chegada do paciente aos setores de atenção em saúde de maior complexidade.

\section{Metodologia}

Trata-se de um estudo qualitativo, baseado na coleta de dados por intermédio da técnica de grupo focal aplicada a cirurgiões-dentistas do município de Porto Alegre atuantes em diferentes realidades laborais de atenção primária em saúde.

\section{Participantes}

O presente estudo teve como público-alvo cirurgiões-dentistas atuantes em 5 (cinco) realidades laborais distintas da APS no município de Porto Alegre: Serviço de Saúde Comunitária do Grupo Hospitalar Conceição, Estratégia de Saúde da Família da Prefeitura Municipal de Porto Alegre, Unidade Básica de Saúde da Prefeitura Municipal de Porto Alegre, serviço de atenção primária do Hospital Moinhos de Vento e Coordenação de Saúde Bucal do Município de Porto Alegre.

Cada serviço foi representado por 2 (dois) profissionais, com exceção dos 2 (dois) últimos, que contou com 1 (um) representante, totalizando uma amostra de 8 integrantes. A amostra caracterizou-se como amostra de conveniência, sendo utilizados como critérios de inclusão profissionais com formação em APS e que estivessem atuando na Atenção Básica. Não foram incluídos profissionais que não possuíssem formação específica em Saúde Pública. Quando havia mais de dois profissionais com estas características, realizou-se sorteio.

Os cirurgiões-dentistas foram convidados pelos pesquisadores através de contato telefônico e, nesse contato, foram detalhados objetivos, procedimentos, cronograma e local da realização da pesquisa.

\section{Instrumentos}

O instrumento para coleta de dados do presente estudo foi a técnica de grupo focal utilizando um roteiro pré-estabelecido e aplicação de questionário estruturado (Quadro 1) confeccionado pelos pesquisadores como dinâmica disparadora da discussão.

\section{Coleta e Análise de Dados}

O grupo focal aconteceu na sala de reuniões de uma das unidades de saúde integrantes do Serviço de Saúde Comunitária do Grupo Hospitalar Conceição. A duração foi estimada em 90 (noventa) minutos e contou com 2 (dois) moderadores e 1 (um) relator, que se deteve nas anotações das informações decorrentes da discussão e nas movimentações não verbalizadas do grupo.

O grupo focal foi estruturado seguindo um roteiro pré-estabelecido pelos pesquisadores, organizado em etapas, que possuíam um tempo aproximado de duração pré-definido. As discussões foram mediadas pelos moderadores e disparadas com base em um questionário estruturado (Quadro 1) com questões abertas, previamente construídas, que abordavam diversos aspectos relacionados ao tema principal, definido como possíveis razões presentes na atenção básica que possam justificar o atraso no diagnóstico de pacientes com câncer bucal.

A reunião foi registrada com auxílio de um gravador de áudio. Posteriormente, as falas foram transcritas para um documento de texto. 
Quadro 1. Questionário estruturado.

\begin{tabular}{|c|c|}
\hline 1 & Na sua opinião, qual o papel do dentista da APS em relação ao diagnóstico de câncer bucal? \\
\hline 2 & Do ponto de vista prático, como você imagina que o dentista deve atuar neste sentido? \\
\hline 3 & Diante de uma suspeita de câncer bucal, como você procederia? \\
\hline 4 & Diante da confirmação de um caso de câncer bucal, como você procederia? \\
\hline 5 & Quais sinais/sintomas levariam você a desconfiar que um caso se trata de câncer de boca? \\
\hline 6 & Como é o fluxo do paciente com suspeita de câncer de boca? \\
\hline 7 & Você imagina que o câncer de boca possa ser diagnosticado precocemente? Justifique. \\
\hline 8 & $\begin{array}{l}\text { Supondo que houvesse atraso no diagnóstico ou no atendimento do paciente portador desta } \\
\text { doença no serviço secundário, quais você imagina que sejam as razões envolvidas? }\end{array}$ \\
\hline 9 & Para quais pacientes está indicada a realização do exame de tecidos moles? \\
\hline 10 & $\begin{array}{l}\text { Você acha que os profissionais envolvidos na equipe além do cirurgião dentista poderiam contribuir } \\
\text { de alguma forma na questão do câncer bucal? Como? }\end{array}$ \\
\hline
\end{tabular}

Após transcrição e digitação das gravações da entrevista grupal, atribuiu-se códigos às identidades dos profissionais entrevistados (A, B, C, $\mathrm{D}$ e E), realizou-se leitura dos textos transcritos, com o intuito de visualizar o panorama geral do material coletado e a criação de categorias representando eixos centrais de discussão onde, posteriormente, foram alocadas as ideias interpretadas a partir das falas transcritas. Uma vez identificados os sentidos atribuídos às ideias, foi realizada síntese da interpretação dos eixos centrais.

Tal metodologia de sistemática e análise de grupos focais segue a mesma linha utilizada previamente por Zacarias e Bavaresco ${ }^{10}$ e Minayo et al. ${ }^{11}$.

\section{Aspectos Éticos}

O presente estudo foi submetido ao Comitê de Ética em Pesquisa do Grupo Hospitalar Conceição. Os participantes do grupo focal receberam um termo de consentimento livre e esclarecido em duas vias de igual teor que foi assinado. Uma via ficou com o pesquisador e outra com o participante.

Os indivíduos tinham a liberdade de recusarse a participar do estudo ou retirar seu consentimento em qualquer fase da pesquisa. Os dados dos entrevistados foram sigilosos e confidenciais.

\section{Resultados}

A amostra do grupo focal, originalmente planejada para ser composta por 8 participantes na metodologia desta pesquisa, teve perda de 3 indivíduos que não compareceram ou não confirmaram participação, sendo realizado, portanto por 5 profissionais de diferentes realidades laborais, sendo 2 mulheres e 3 homens. A duração da discussão do grupo focal foi de 1 hora e 34 minutos. As respostas dos entrevistados foram divididas nas seguintes categorias: Profissional, Equipe, Comunidade e Rede de serviços.

\section{Profissional}

Os entrevistados relataram uma série de atividades passíveis de serem realizados pelo profissional da APS no que tange ao diagnóstico de câncer bucal.

É o primeiro contato da pessoa, ele é o responsável pela identificação e pela continuidade desse contato. A partir desta fala, o profissional A sugere que mesmo com o paciente devidamente encaminhado ao setor secundário, o cirurgiãodentista deve se responsabilizar pela longitudinalidade do cuidado.

Além disso, outras atribuições que cabem ao cirurgião-dentista são capacitações de equipe e edu- 
cação em saúde, bem como o trabalho de vigilância calcado em ações de prevenção em saúde na área adscrita. Neste contexto, a capacitação voltada para a própria categoria parece ser ineficaz.

Fazer capacitação. Gente...quem é que nunca participou de uma capacitação de estomatologia? Mais de uma? Farmacologia? Quantas? Porque a capacitação no modelo de transmissão de conhecimento vai lá a pessoa detentora do saber passa a informação, estudo de caso, as pessoas prestam atenção e voltam para a unidade de saúde. Quantos conseguem passar isso para unidade de saúde? Primeira coisa seria capacitar as pessoas, mas todo ano no município tem uma capacitação de estomatologia... todo ano desde que eu entrei a gente não consegue rastrear as pessoas então eu acho que capacitar somente não resolve. (A)

Segundo os próprios profissionais, existe evasão, reflexo do desinteresse da categoria em se atualizar, além disso ficam claras as controvérsias em relação ao modelo atual da educação permanente:

Já acho difícil o pessoal comparecer. (C)

A minha opinião é porque a capacitação é um disparador da absorção de conhecimento. Acho que as pessoas deveriam fazer uma busca... falar sobre 10 tipos de alterações de tecidos moles durante uma manhã hoje eu vou lembrar, ao sair da reunião, eu lembro de 8. Amanhã eu lembro de 7, daqui a uma semana eu vou lembrar de 5 e como não é uma coisa corriqueira então a gente acaba esquecendo e as pessoas acabam não indo estudando [...] (A)

Mas eu acho que a capacitação não muda a forma como as pessoas trabalham. Elas vêm aqui, acham tudo muito bonito, mas quando voltam continuam na mesma. (B)

Paralela às incumbências do cirurgião-dentista, é discutida também a importância da formação do profissional proporcionada pela qualificação oferecida pela especialização ou pela residência na área da APS:

Dentro do processo de trabalho, [o trabalho multidisciplinar] depende muito da formação das pessoas e o quanto se percebe que aquilo é importante. (E)

Os entrevistados se mostraram aparentemente esclarecidos a respeito das características clínicas que podem suscitar a suspeita de câncer bucal e acreditam que tal enfermidade possa ser diagnosticada precocemente. Observou-se consenso no que tange à indicação para realização de exame bucal: não deve se limitar apenas aos pacientes que tenham perfil de risco comprovado epidemiologicamente; ele deve estender-se a todos os indivíduos.
Curiosamente, um dos profissionais coloca, que o histórico familiar de câncer, em um contexto definido, serve como situação que permite ao paciente reconhecer a enfermidade e aderir às condutas necessárias, sendo, portanto, o indivíduo, da mesma forma, promotor do autocuidado:

[...] também legal é a questão do próprio histórico familiar. Invariavelmente, as pessoas relatam ah na minha família já teve câncer semelhante, né? Não que dizer que seja obrigatório, mas até a pessoa começar a perceber um pouco mais da gravidade do problema também que daí começa a fechar vários pontos [...]. (E)

Observa-se que existe falha no diagnóstico precoce na medida em que as ações oferecidas pela unidade de saúde voltam-se para casos em que já ocorre alguma sintomatologia:

[...] então assim, a pessoa tenta consultar, ela quer consultar de urgência que às vezes o foco da consulta de urgência é uma dor específica e não por causa da lesão que às vezes é assintomática, né? E que faz com que, às vezes, quando a pessoa acesse mesmo é por outra razão, que daí indiretamente se descobre [...] (E)

\section{Equipe}

Por mais definido que seja o papel do cirurgião-dentista no âmbito assistencial, as atividades multiprofissionais apresentam-se oportunas para a realização do diagnóstico, como referido:

A gente tem algumas oportunidades assim, na verdade de fazer isso a nivel populacional de uma forma mais tranquila que a gente acaba perdendo (E)

$$
[\ldots]
$$

A campanha da vacinação do idoso que é um momento legal da gente estar pensando em uma estratégia de rastreamento e tal que a gente tá deixando passar por detalhe (E)

A partir desta eventualidade, que transcende o assistencialismo do consultório, abre-se a possibilidade do rastreamento de casos suspeitos de câncer bucal. É reforçado o fato de que o câncer bucal tem fatores de risco comuns a outras enfermidades e o que efetivamente a equipe realiza a partir dessa reflexão:

[...] cirurgiões-dentistas verem no coletivo das pessoas quais os fatores de risco e ver que o câncer de boca assim como outros cânceres tem fatores de risco comum e o quanto estamos atuando nesses fatores de risco. (A)

Descobre-se que existe um diferencial em relação ao trabalho multidisciplinar. Houve relato de que em muitas unidades básicas de saúde, in- 
clusive, ele é ausente. Há queixas de falta de discussão, de diálogo e de reunião de equipe, situações estas que permitiriam trocas de experiências e captação de pacientes:

[...] e é muito difícil ter esse trabalho em equipe em que todas as pessoas estejam atentas aos problemas e as pessoas entenderem que elas terem que usar o chapéu protetor por trabalharem no sol é importante... (B)

Tem UBS que não tem reunião de equipe. A gente briga com secretário de saúde, coordenador porque a gente não consegue ter reunião de equipe. Então é bem difícil

$\mathrm{O}$ agente comunitário parece desempenhar função notadamente importante em uma equipe de saúde. É este profissional que atua em múltiplas vertentes da APS, inclusive trazendo retorno de pacientes acompanhados:

E tudo a gente consegue se comunicar bem assim... e com as agentes de saúde também. Então agente de saúde cada vez me traz um laudo diferente [...] superbem assim. (C)

E eu acho importante a agente de saúde...para que ela nos traga o feedback. As minhas [agentes de saúde], dos casos que eu tive, me ajudaram muito. Até hoje, elas me trazem. Bom, até às vezes, o paciente não consegue... e a gente tá sempre dando o feedback de como está, como não está. (B)

O grupo focal referiu que a capacitação é uma ferramenta importante na transmissão de conhecimento, mas adverte que é insuficiente. Os entrevistados ponderaram que os profissionais da equipe devem cogitar abordagens baseadas no perfil da população.

Suscitou-se, no grupo, a reivindicação de que o cirurgião-dentista esteja presente no diversos espaços oferecidos pela unidade de saúde, já que a categoria se percebe com participação limitada:

[...] a gente tava discutindo hipertensão e diabetes na reunião [...] e vários coordenadores colocaram a associação da hipertensão e da diabetes com a questão do tabagismo e poucas unidades, acho que uma talvez, foi falado claramente da importância do dentista no grupo... e a gente teve que fazer uma pergunta que grupo de tabagismo é esse que não avalia também as questões de saúde bucal dessas pessoas? (E)

Além disso, é importante que se constate que o cirurgião-dentista é capaz de avaliar outras situações de saúde que não aquelas estritamente odontológicas:

$\mathrm{Na}$ realidade... e tem uma coisa que eu acho que é importante a gente começar a entender o seguinte... o mais importante para o municipio, não importa se é o enfermeiro, médico ou dentista.
Não concordo que o dentista não pudesse [avaliar outras questões de saúde além daquelas relacionadas à saúde bucal], porque tem muito dentista fazendo grupos de tabagismo, mas não deixar de registrar por causa disso. (A)

Como é que dentista não pode fazer avaliação de tabagismo? Como é que dentista não pode fazer de álcool e drogas? No PMAQ agora quem faz avaliação de dependência de álcool e drogas e essas coisas é só médico; eu acho que a gente vai ter que lutar para que isso seja contabilizado também. Nem que seja para ser reconhecido dentro da equipe, seja revisto o nosso papel de olhar dente. (E)

Acho que todo mundo que tem contato com o público. (A) foi uma das falas que sintetizou o pensamento de que todos os membros da equipe, como médicos, enfermeiros e técnicos, têm o papel de observar a boca dos usuários e aferir quando algo está diferente do normal. É salientado por um dos participantes do grupo focal que os demais profissionais, que não o cirurgião-dentista, não examinam nem diagnosticam de fato as lesões de boca, mas podem se capacitar para aconselhar o paciente e informá-lo da necessidade de visitar os profissionais da saúde bucal.

\section{Comunidade}

O viés usuário também consta como participante do processo de diagnóstico de câncer bucal. Ele pode ser, concomitantemente, receptor e transmissor de informações passadas pelo profissional de saúde. Ademais, é extremamente importante que haja participação efetiva da comunidade no que tange ao autocuidado:

Outra questão que a gente pode estimular é a questão do autoexame, que é pouco difundido. A gente não tem essa prática. A pessoa se examinar... enfim, né? Promover isso. (D)

Os cirurgiões-dentistas referem lacuna referente à adesão do paciente que, muitas vezes, pode não ir à consulta marcada ou até mesmo recusar $o$ atendimento. Neste sentido, ratifica-se a necessidade da comunidade valorizar o serviço oferecido pelos profissionais e corresponsabilizar-se pela própria saúde:

Um desses que eu encaminhei, eu encaminhei, ele não foi, eu liguei, ele não quis ir, ele não foi, ele não foi, até que tava morrendo. Daí, quando ele tava morrendo, ele decidiu se tratar, mas não adiantou... não adiantou eu, não adiantou médico, ninguém... ficaram insistindo que ele precisava se tratar há muito tempo e olha... a gente ficou 1 ano e meio. (C) 
Com certeza. Acho que também é responsabilidade do paciente também. Depende dele ir. Só que a nossa função é fazer o diagnóstico precoce e, mesmo que ele não diga que eu fui lá várias vezes quando ele tinha condição de caminhar e era fora da área, ele tocou quase que à pedrada, mas a gente voltava lá. Eu já fiz de tudo... não, não, lavei as minhas mãos. (A)

\section{Rede de Serviços}

As possibilidades ofertadas pela rede de atenção não são uniformes. Observam-se falhas aqui representadas pela falta de centros de especialidade para encaminhamento em determinados municípios. Nos municípios que não dispõem de atenção secundária da rede, os profissionais utilizam os serviços de estomatologia oferecidas por entidades em Porto Alegre.

Referiu-se que problema não é o encaminhamento ao estomatologista, mas à atenção terciária em caso de confirmação do câncer bucal. Houve relato de que, quando diagnosticado pelo estomatologista, o paciente retorna à unidade básica para, a partir dali, ser encaminhado via sistema informatizado (uso de referência e central de marcação):

Eu acho que à estomato chega rápido, o problema é depois da estômato. Esse paciente, ele tava com uma lesão bem séria e ficou de fevereiro a junho esperando. (B)

A organização da demanda a partir do mecanismo de referência e contrarreferência foi interpretado, a partir das falas dos profissionais, como ponto-chave para o fluxo de pacientes. Por um lado, a referência, quando bem utilizada, auxilia os profissionais de níveis de atenção mais complexos a realizarem o diagnóstico definitivo. Por outro lado, o retorno do setor secundário se faz importante mesmo que não se confirme o diagnóstico da enfermidade em questão. $\mathrm{O}$ conhecimento do desfecho, formatado pela interpretação do especialista, somado ao diagnóstico clínico realizado no acesso à atenção primária, é uma ação inerente à coordenação do cuidado.

A importância, clara nas falas dos entrevistados, do documento de referência não determina, entretanto, que ela seja utilizada de forma adequada por todos os profissionais da rede. O correto preenchimento e a qualidade dos registros varia conforme o profissional:

Apesar de que, me corrige se eu estiver equivocado, dentro de todas as especialidades, quem melhor escreve é o estomatologista, né? (A)

[...] Por exemplo, encaminhamento para periodontia: Eu encaminho à periodontia. Ponto. Não diz se tem bolsa, não tem bolsa, onde tem mais bolsa (A)

Observamos que existe uma diferença significante de fluxos entre os municípios para encaminhamento do paciente com suspeita de câncer bucal. Há municípios que apresentam falha na rede de atenção por não apresentarem centros de referências para encaminhamento. Além disso, tal falha na rede de atenção não é válida para todos os municípios, a exemplo de Porto Alegre, que pode encaminhar os pacientes via sistema informatizado ou via comissão de saúde, ferramenta esta que geralmente é utilizada em situações que exigem maior urgência:

Comissão de saúde é mais rápido, porque a comissão de saúde pode conseguir de um dia para outro assim. Uma semana. O informatizado, às vezes tu consegue até rapidamente, acho que... quando demorava mais que 1 semana ou 2, pela comissão de saúde tu conseguia em 2 dias... (A)

\section{Discussão}

Apesar de a literatura apresentar alguns dados pertinentes que definem $o$ atraso da intervenção, ainda não há consenso com relação a um intervalo de tempo "aceitável" dentro do qual o diagnóstico do câncer deveria acontecer. Outros autores indicam prazos arbitrários que seriam suficientes para se estabeleça alguma resolutividade através do diagnóstico e acompanhamento?

Frente a este cenário, a literatura sugere a implementação de programas de rastreamento e/ou de prevenção de cunho regional ou nacional, programas de educação permanente e continuada para os profissionais de saúde em geral e da categoria e realização de exames clínicos periódicos incluindo a avaliação da mucosa bucal como medidas necessárias para reduzir o atraso no diagnóstico ${ }^{4}$. Além disso, com o intuito de facilitar o diagnóstico precoce, é importante que os fatores de risco sejam identificados e, quando possível, controlados ${ }^{4,6,12-14}$.

Diferentemente da pesquisa quantitativa, $o$ presente estudo não visou enumerar ou medir um determinado evento, mas buscar significado no contexto ${ }^{15-18} \mathrm{em}$ que os cirurgiões-dentistas se inserem. Neste sentido, a técnica do grupo focal, proveniente de metodologia de cunho qualitativo, converge para o objetivo deste estudo a partir da compreensão e descrição da percepção do profissional a respeito das razões que justificam $\mathrm{o}$ atraso do paciente com suspeita de câncer bucal aos níveis de maior complexidade. Os resultados desta pesquisa foram sistematicamente 
divididos por eixo central, conforme proposto na metodologia: Profissional, Equipe, e Comunidade e Rede de Serviços.

Em relação ao eixo Profissional, os cirurgiões-dentistas apontam para falha na identificação precoce, já que uma gama de profissionais atua enfaticamente sobre os casos que já apresentam alguma sintomatologia. A mesma justificativa para atraso já havia sido relatada no estudo de Brockelhurst et al. ${ }^{19}$. Kantola et al. ${ }^{20}$ corrobora tal dado, ao pontuar que o universo de pacientes que procura o atendimento odontológico, vem por outros motivos que não os relacionados à lesão suspeita, sendo o rastreamento obtido de forma oportunista. Reforça-se, portanto, a necessidade de realização de exame clínico minucioso para todos os pacientes e aconselhamento específico para aqueles que relatarem características comuns ao perfil de risco para o câncer bucal ${ }^{21}$.

A educação dos profissionais, nos moldes atuais, é pouco efetiva. Segundo o grupo focal, a justificativa para tal ponderação se dá na medida em que a transmissão de conhecimento basicamente parece ser uma alternativa pouco atraente para o profissional. Além disso, analisando a partir da perspectiva da gestão dos dentistas como servidores, não há meios que "obriguem" a presença do profissional, tampouco que busquem avaliar o quanto foi absorvido de informação.

A partir do momento em que o profissional se abstém de realizar os programas de atualização oferecidos pelo serviço em que se situa ${ }^{22}$, o processo diagnóstico-clínico, altamente necessário para o rastreamento de lesões potencialmente malignas ${ }^{23,24}$, acaba por ser prejudicado.

Ainda se observa queixa de número de reuniões de equipe insuficientes. A falta destes espaços de discussão aparentemente indica insuficiente trabalho multidisciplinar. A falta de diálogo diagnosticada pelos próprios cirurgiões-dentistas com as demais categorias empobrece o fluxo de pacientes em potencial para o levantamento de suspeitas já que as reuniões de equipe, seminários e demais espaços de discussão, além de tornarem oportuna a troca de informações, são mecanismos fundamentais para que se efetive a interdisciplinaridade preconizada pela atenção primária em saúde ${ }^{25}$. Wade et al..$^{26}$ já haviam encontrado resultados semelhantes ao observar que os médicos captam mais pacientes com suspeita de câncer de boca que os próprios cirurgiõesdentistas. Somado a este dado, relatos de outros estudos ponderam que os próprios pacientes tendem a procurar outros profissionais, que não o cirurgião-dentista, em primeira instância na ocor- rência de uma lesão de boca ${ }^{8}$. Uma vez estagnado pelo assistencialismo em uma determinada categoria no universo de uma unidade de saúde, o paciente acaba por ser subdiagnosticado.

Além disso, a existência de equipe alheia a conhecimentos básicos do câncer bucal justifica a necessidade de troca de informações entre categorias $^{27,28}$. A necessidade de educação permanente a respeito do câncer, bastante enfatizada na literatura, se torna mandatória com intuito de oferecer aos dentistas e aos demais profissionais o mínimo de conhecimento que possibilite a participação ativa da equipe na captação de pacientes.

Os entrevistados apontam que a comunidade carece de educação em saúde, realidade está já retratada em estudos prévios ${ }^{8,29,30}$. A partir desta premissa, a aprendizagem, no que tange ao autoexame ${ }^{31,32}$ frente à ineficácia do rastreamento, se apresenta como possibilidade de estimular a participação ativa do paciente no processo saúde-doença. Além disso, é de suma importância que se saiba discernir que uma situação de saúde assintomática nem sempre é sinônimo de saúde.

A frequência de visitas ao dentista está diretamente ligada à probabilidade de um diagnóstico precoce de uma lesão suspeita ${ }^{33}$. Logo, é desejável que haja a corresponsabilização do paciente pelo seu próprio estado de saúde e pela procura dos serviços. A efetivação desta conduta deve ocorrer, de fato, a partir do entendimento de que a recusa ou evasão às consultas provavelmente agravará uma enfermidade estabelecida.

Com relação à rede de serviços, o relato dos profissionais indica que o atraso do encaminhamento pode estar relacionado à qualidade da informação fornecida nos documentos de referência e contrarreferência, problema este já apontado em outros levantamentos ${ }^{34-40}$. Ainda que não seja pontualmente relacionada à rede, mas sim às conexões entre os níveis de atenção, o instrumento é uma peça fundamental para o processo diagnóstico.

A partir de uma ferramenta de referência adequadamente preenchida é possível munir o profissional a seguir na cadeia dos níveis de atenção de informações contextualizadoras e essenciais para o desfecho diagnóstico. A outra via, a contrarreferência, desempenha da mesma forma o elo de comunicação que possibilitará a continuidade do cuidado e a determinação de condutas frente à entidade patológica diagnosticada. Este cenário sugere, consequentemente, que existe alguma dificuldade de comunicação entre profissionais de diferentes níveis de atenção.

Curiosamente, os profissionais do grupo focal não criticam o acesso à atenção secundária, 
ainda que alguns serviços de atenção primária não disponham de referência regionalizada para encaminhamento de pacientes e acabem por depender de entidades para a realização de biópsia e de diagnóstico histopatológico. O nó crítico de fato, em relação à rede de serviços, está aparentemente relacionado à dificuldade de acesso à atenção terciária, que já abrange atuação do cirurgião de cabeça e pescoço, dentre outros profissionais.

\section{Conclusão}

A análise realizada a partir da percepção dos cirurgiões-dentistas a respeito das razões que possam justificar o atraso do encaminhamento de pacientes com suspeita de câncer de boca permitiu observar que é atribuído um valor positivo no que tange à necessidade de estabelecimento de ações que primem pelo diagnóstico precoce, tanto no âmbito clínico-tecnicista quanto no de gestão.

$\mathrm{O}$ atraso dos pacientes com suspeita de câncer bucal, avaliada pelo eixo Profissional transcende a compreensão que o olhar clínico, minucioso, muitas vezes foca-se em episódios imediatistas sintomáticos. Os sinais e os sintomas clínicos mais evidentes acabam por anular um filtro diagnóstico. Em suma, a obviedade clínica apresentada por uma determinada queixa do paciente no primeiro acesso é priorizada em detrimento das enfermidades assintomáticas, que por ora possam estar se desenvolvendo concomitantemente ou inclusive serem geradoras de tal processo agudo.

A equipe, quando não valoriza o trabalho multidisciplinar, sofre prejuízo ao perceber ineficaz um mecanismo promissor de captação de pacientes. O paciente que acessa o serviço de saúde e não é assistido por um profissional com um olhar ampliado tende a ter como resolutiva apenas a queixa principal que o motivou a comparecer na unidade. A eventualidade de se checar uma lesão que não seria o motivo principal da vinda do paciente ao profissional de saúde, que não o cirurgião-dentista, terá grandes probabilidades de ser subdiagnosticada.

Ressalta-se, em relação à Rede de Serviços, que a qualidade do instrumento de referência e contrarreferência está intimamente relacionada com a possibilidade do atraso do paciente. Uma vez mal preenchido, ou até mesmo não preenchido, o documento tende a se tornar uma simples ficha de acesso. Ainda neste eixo, o agravante rela- cionado às comorbidades oriundas do câncer bucal já diagnosticado é o atraso à intervenção propriamente dita que, por sua vez, aumenta o tempo de convalescência do indivíduo e as chances de sequela funcional.

A educação em saúde, representada em diversas vertentes, parece ser comum à maioria dos eixos centrais. A tríade profissional-equipe-comunidade caracteriza um universo a parte em que as informações de alimentação e retroalimentação e as trocas destas constroem um perfil único em que todas as partículas participam do processo ativo de diagnóstico. A partir do momento em que as atitudes curativas se sobrepõem às preventivas provavelmente a tríade proposta se apresenta falha em algum dos alicerces.

$\mathrm{O}$ relato e o apontamento de falhas indica a existência de parecer crítico por parte dos profissionais, etapa esta mandatória para o estímulo de estratégias efetivas com escopo voltado para a otimização de acesso e fluxo de pacientes. Para tanto, o presente estudo sugere o estímulo à discussão intersetorial, englobando representações de todos os níveis de atenção e educações permanentes moldadas ao perfil apresentado pela tríade profissional-equipe-comunidade.

No universo da atenção primária, o rastreamento de lesões bucais concomitante a outras atividades na unidade somado à educação em saúde ${ }^{41}$ (para profissionais e para usuários) parecem ser ferramentas eficazes alinhadas aos princípios do Sistema Único de Saúde.

Sugere-se a realização de mais estudos com o intuito de aprofundar as questões que justifiquem o atraso dos pacientes aos setores de maior complexidade.

\section{Colaboradores}

EM Lombardo, CS Bavaresco, VC Carrard e AR Cunha participaram igualmente de todas as etapas de elaboração do arquivo. 


\section{Referências}

1. Instituto Nacional do Câncer (Inca). Estimativa 2010: incidência de câncer no Brasil. Rio de Janeiro: Inca; 2009. [site da internet]. [acessado 2012 jul] Disponível em: http://wwwl.inca.gov.br/estimativa/ 2012/

2. Iglesias R, Jha P, Pinto M, Costa e Silva VL, Godinho J. Documento de discussão - saúde, nutrição e população (HNP). Controle do tabagismo no Brasil: resumo executivo. Epidemiol Serv Saude 2008; 17(4):301-304.

3. Laranjeira R, Pinsky I, Zaleski M, Caetano R. I Levantamento nacional sobre os padrões de consumo de álcool na população brasileira. [site da internet]. [acessado 2012 jul]. Disponível em: http:/ /www.obid.senad.gov.br

4. Onizawa K, Nishihara K, Yamagata K, Yusa H, Yanagawa T, Yoshida $\mathrm{H}$. Factors associated with diagnostic delay of oral squamous cell carcinoma. Oral Oncol 2005 jan; 39(8):781-789.

5. Mcleod NM, Saeed NR, Ali EA. Oral cancer: delays in referral and diagnosis persist. Br Dent J 2005; 198(11):681-684

6. Sargeran K, Murtomaa H, Safavic SMR, Teronen O. Delayed Diagnosis of Oral Cancer in Iran: Challenge for Prevention. Oral Health Prev Dent 2009; 7(1):69-76.

7. Gao W, Guo CB. Factors Related to Delay in Diagnosis of Oral Squamous Cell Carcinoma. J Oral Maxillofac Surg 2009; 67(5):1015-1020.

8. Santos LC, Batista Ode M, Cangussu MC. Characterization of oral cancer diagnostic delay in the state of Alagoas. Braz J Otorhinolaryngol 2010; 76(4):416-422.

9. Gomez I, Seoane J, Varela-Centelles P, Diz P, Takkouche B. Is diagnostic delay related to advancedstage oral cancer? A meta-analysis. Eur J Oral Sci 2009; 117(5):541-546.

10. Zacarias IR, Bavaresco CS. Conhecendo a realidade dos catadores de materiais da Vila Dique: visões sobre os processos de saúde e doença. Rev Tex Contex 2009; 8(2):293-305.

11. Minayo MCS, Assis SG, Oliveira RVC. Impacto das atividades profissionais na saúde física e mental dos policiais civis e militares do Rio de Janeiro. Cien Saude Colet 2011; 16(4):2199-2209.

12. Scott SE, Grunfeld EA, Mcgurk M. The idiosyncratic relationship betweendiagnostic delay and stage of oral squamous cell carcinoma. Oral Oncol 2005; 41(4):396-403.

13. Peacock ZS, Pogrel MA, Schmidt BL. Exploring the Reasons for Delay in Treatment of Oral Cancer. $J$ Am Dent Assoc 2008; 139(10):1346-1352.

14. Brouha XDR, Tromp DM, Hordijk GJ, Winnbust JAM, Leeuw JRJ. Oral and pharyngeal cancer: analysis of patient delay at different tumor stages. Head Neck 2005; 27(11):939-945.

15. Trad LAB. Grupos focais: conceitos, procedimentos e reflexões baseadas em experiências com o uso da técnica em pesquisas de saúde. Physis 2009; 19(3):777-796.

16. Morgan DL. Focus groups as qualitative research. Londres: Sage Publications; 1997.
17. Kitzinger J. Focus groups with users and providers of health care. In: Pope C, Mays N, editors. Qualitative research in health care. $2^{\text {nd }}$ ed. London: BMJ Books; 2000.

18. Neves JL. Pesquisa qualitativa: características, usos e possibilidades. Cad Pesq Adm 1996; 1(3):1-5.

19. Brocklehurst PR, Baker SR, Speight PM. Factors affecting the referral of potentially malignant lesions from primary dental care: a pilot study in South Yorkshire. Prim Dent Care 2009; 16(1):13-18.

20. Kantola S, Jokinen K, Hyrynkangas K, Mäntyselkä $\mathrm{P}$, Alho OP. Detection of tongue cancer in primary care. Br J Gen Pract 2001; 51(463):106-111.

21. Otoh EC, Johnson NW, Olasoji HO, Danfillo IS, Adeleke OA. Intra-oral carcinomas in Maiduguri, north-eastern Nigeria. Oral Dis 2005; 11(6):379-385.

22. McCann MF, Macpherson LM, Binnie VI, Stephen KW. A survey of Scottish primary care dental practitioners' oral cancer-related practices and training requirements. Comm Dent Health 2000; 17(1):24-30.

23. Macpherson LM, McCann MF, Gibson J, Binnie VI, Stephen KW. The role of primary healthcare professional in oral cancer prevention. Br Dent $J$ 2003; 195(5):277-281.

24. Alvi A. Oral cancer: how to recognize the danger signs. Postgrad Med 1996; 99(4):149-152,155-156.

25. Vasconcellos VC. Trabalho em equipe na saúde mental: o desafio interdisciplinar em um caps. Rev eletr saude mental alcool drog 2010; 6(1):1-16.

26. Wade J, Smith H, Hankins M, Llewellyn C. Conducting oral examinations for cancer in general practice: what are de barriers? Fam Pract 2010; 27(1):77-84.

27. Llewellyn CD, Johnson NW, Warnakulasuriya S. Factors associated with delay in presentation among youngsters. Oral Surg Oral Med Oral Pathol Oral Radiol Endod 2004; 97(6):707-713.

28. Van der Waal I, de Bree R, Brakenhoff R, Coebergh JW. Early diagnosis in primary oral cancer: is it possible? Med Oral Patol Oral Cir Bucal 2011; 16(3):e300-305.

29. Tomar SL, Logan HL. Florida adults'oral cancer knowledge and examination experiences. J Public Health Dent 2005; 65(4):221-230.

30. Tromp DM, Brouha XD, Hordijk GJ, Winnubst JA, de Leeuw JR. Patient factors associated with delay in primary care among patients with head and neck carcinoma: a case-series analysis. Fam Pract 2005; 22(5):554-559.

31. Martins AMEBL, Barreto SM, Pordeus IM. Fatores relacionados à autopercepção da necessidade de tratamento odontológico entre idosos. Rev Saude Pub 2008; 42(3):487-496.

32. Marinho L, Costa-gurgel M, Cecatti J, Osis M. Conhecimento, atitude e prática do auto-exame das mamas em centros de saúde. Rev Saude Pub 2003; 37(5):576-582.

33. Yu T, Wood RE, Tenenbaum HC. Delays in diagnosis of head and neck cancers. J Can Dent Assoc 2008; 74(1):61. 
34. Juliani C, Ciampone M. Organização do sistema de referência e contra-referência no contexto do Sistema Único de Saúde: a percepção de enfermeiros. Rev Esc Enf USP 1999; 33(4):323-333.

35. Nicoletto S, Cordoni Júnior L, Costa N. Consórcios Intermunicipais de Saúde: o caso do Paraná, Brasil. Cad Saude Pub 2005; 21(1):29-38.

36. Melo EMC, Assunção AA, Ferreira RA. O trabalho dos pediatras em um serviço público de urgências: fatores intervenientes no atendimento. Cad Saude Pub 2007; 23(12):3000-3010.

37. Rodgers J, Macpherson LM, Smith GL, Crighton AJ, Carton AT, Conway DI. Characteristics of patients attending rapid access clinics during the West of Scotland Cancer Awareness Programme oral cancer campaign. Br Dent J 2007; 202(11):E28; discussion 680-681.

38. Oliveira S, Albuquerque F. Programa de saúde da família: uma análise a partir das crenças dos seus prestadores de serviço. Psicol Soc 2008; 20(2):237246.

39. Zambenedetti G, Perrone C. O processo de construção de uma rede de atenção em saúde mental: desafios e potencialidades no processo de reforma psiquiátrica. Physis 2008; 18(2):277-293.

40. Machado L, Colomé J, Beck C. Estratégia de saúde da família e o sistema de referência e de contrareferência: um desafio a ser enfrentado. $R$ Enferm UFSM 2011; 1(1):31-40.

41. Dalcanale C, Valdemar A, Vendruscolo C, Argenta C. Estratégia de saúde da família e análise da realidade social: subsídios para políticas de promoção da saúde e educação permanente. Cien Saude Colet 2011; 16(11):4295-4306.

Artigo apresentado em 18/03/2013

Aprovado em 25/09/2013

Versão final apresentada em 12/10/2013 